\title{
The Association Between Erectile Dysfunction and Subclinical Hypothyroidism in Males with Type 2 Diabetes Mellitus
}

\author{
๑ Ridvan Sivritepe, ๑ Sema Ucak Basat*, ๑ Arzu Baygul** , ๑ Okcan Basat*** \\ Istanbul Medipol University, Pendik Hospital, Clinic of Internal Medicine, Istanbul, Turkey \\ *University of Health Sciences Turkey, Umraniye Training and Research Hospital, Clinic of Internal Medicine, Istanbul, Turkey \\ ${ }^{*}$ Koc University Faculty of Medicine, Department of Basic Sciences, Istanbul, Turkey \\ ***University of Health Sciences Turkey, Gaziosmanpasa Taksim Training and Research Hospital, Clinic of Family Medicine, Istanbul, Turkey
}

\section{Abstract}

\begin{abstract}
Aim: Overt hypothyroidism is known to affect sexual functions, but data on subclinical hypothyroidism (SCH) are insufficient. We aimed to investigate the relationship between erectile dysfunction (ED) and SCH in men with type 2 Diabetes Mellitus.

Methods: This cross-sectional study included 117 diabetic patients aged between 45-70 years who applied to our outpatient clinic between March and June 2018. Biochemical blood tests and levels of hormones were analyzed. International erectile function index-5 (IIEF-5) questionnaire was applied for the assessment of ED. According to the IIEF-5 questionnaire scores, patients were grouped as severe ED ( $n=47)$, moderate ED ( $n=46)$, and no ED ( $n=24)$. Patients were also grouped according to the level of thyroid-stimulating hormone (TSH) into 3 groups; 0.27-2.49 mU/I ( $n=58), 2.5-4.2 \mathrm{mU} / \mathrm{I}(\mathrm{n}=33)$, and $>4.2 \mathrm{mU} / \mathrm{I}(\mathrm{n}=26)$. Statistically significance level was set at 0.05 .
\end{abstract}

Results: $40 \%$ of the patients had severe ED and 39\% moderate ED, while $21 \%$ had no ED. The TSH levels were significantly different between the ED groups $(p<0.001)$. A significant negative correlation was found between the IIEF- 5 score and the TSH levels ( $p<0.001$, $r=-0.453$ ). The IIEF-5 score, and duration of ED were significantly different between the TSH groups (both; $p<0.001)$.

Conclusions: SCH is closely associated with ED in diabetic men. So, we recommend conducting thyroid function tests in diabetic men with ED and screening for ED in men with SCH.

Keywords: Male, thyrotropin, diabetes mellitus, type 2, erectile dysfunction, hypothyroidism

\section{Introduction}

Type 2 Diabetes Mellitus (T2DM), characterized by hyperglycemia, is a metabolic disorder resulting from insulin resistance, insufficient insulin secretion, or excessive glucagon secretion (1). There are two main polygenetically formatted basic defects in T2D, which is a progressive disease. These are insulin resistance and insulin secretion defect in beta cells (2).

Erectile dysfunction (ED), which is defined as the persistence of insufficient erection and/or failure to maintain an adequate erection for successful sexual intercourse is more common in men with T2DM (3). Diabetic ED resulting from endothelial dysfunction is known to be associated with cardiovascular diseases, obesity, hypertension, metabolic syndrome, and aging (46).

Hyper and hypothyroidism are the main thyroid diseases that have negative effects on the male reproductive system (7). Short-term hypothyroidism has no significant effect in men, but long-term hypothyroidism has been shown to impair male reproductive functions (8). Subclinical hypothyroidism $(\mathrm{SCH})$ is a biochemical definition in which high levels of thyroid stimulating hormone (TSH) are detected when serum-free thyroid hormone levels are normal (9). It has been shown that $\mathrm{SCH}$, which affects many metabolic systems, is also associated with insulin

Address for Correspondence: Ridvan Sivritepe, Istanbul Medipol University, Pendik Hospital, Clinic of Internal Medicine, Istanbul, Turkey 
resistance (10). The pathophysiology of $\mathrm{SCH}$ and ED in these patients is multifactorial $(3,9)$. Both $\mathrm{SCH}$ and ED are conditions that are increasingly prevalent, especially in the middle-aged and elderly diabetic male population, and cause metabolic and sexual dysfunction and reduce the quality of life.

In our study, we aimed to evaluate the possible relationship, which has not been evaluated before, between ED that occurs because of endothelial dysfunction and $\mathrm{SCH}$ that causes microscopic endothelial oedema and atherosclerosis in patients with T2DM.

\section{Methods}

\section{Study Design}

This study was designed as a cross-sectional study and was approved by the Local Ethics Committee (University of Health Sciences Turkey, Umraniye Traning and Research University Hospital Ethics Committee date: 23.02.2018; number: B, 10,1, TKH.4.34.H.GP.0.01/20). It was carried out in accordance with the Helsinki Declaration. Written informed consent was obtained from all participants. One hundred twenty-two male patients who applied to the diabetes outpatient clinic of our hospital were included in the study in order of admission according to the power analysis results. The study was conducted with 117 patients, as five patients left voluntarily after being included in the study. Patients between the ages of 45 and 70 years with a diagnosis of T2D, who have not received thyroid replacement therapy, have normal kidney and liver functions, and have a normal lifestyle with regular physical activity were included. T2DM was diagnosed according to the criteria of the American Diabetes Association (11). The exclusion criteria of the study include; type 1 diabetes mellitus, history of treated or untreated thyroid disease, taking medications that may affect thyroid functions (amiodarone, furosemide, glucocorticoids, iodine etc.), malignancy, hyperprolactinemia, major pelvic surgery, prostate cancer, abnormal rectal examination findings, prostatectomy, severe cardiovascular and neurovascular disease, acute cerebrovascular accident, acute or chronic infection, uncontrolled diabetes, major psychiatric diseases, and diabetic neuropathy.

A detailed anamnesis was taken from all patients and physical examinations were performed [weight, height, body mass index (BMI), waist circumference and blood pressure]. BMI was calculated by dividing weight $(\mathrm{kg})$ by height in meters squared $\left(\mathrm{m}^{2}\right)$. Duration of diabetes and erectile dysfunction, daily number of cigarettes smoked, and use of antihypertensive drugs and anti-hyperlipidemic drugs of all participants were recorded. The patients were divided into 3 groups according to their TSH levels as 0.27-
$2.49 \mathrm{mU} / \mathrm{l}(\mathrm{n}=58), 2.5-4.2 \mathrm{mU} / \mathrm{l}(\mathrm{n}=33)$, and $>4.2 \mathrm{mU} / \mathrm{l}$ $(n=26)$ (Figure 1).

\section{Evaluation of Erectile Dysfunction}

The international index of erectile function (IIEF-5) questionnaire was applied to all patients to evaluate ED (12). IIEF-5 questionnaire scores range between 5 and 25 . This questionnaire has been translated into Turkish and its validity and reliability have been previously tested in Turkey (13). Patients were divided into 3 groups according to their IIEF-5 questionnaire scores. The groups were defined as the following: no ED between 21 and $25 \quad(n=24)$, moderate ED 11 and $20(n=46)$ and severe ED between 5 and $10(n=47)$ (Figure 1).

\section{Evaluation of Subclinical Hypothyroidism}

$\mathrm{SCH}$ is defined as the detection of high TSH levels while free thyroid hormone levels in the serum are normal (14). The normal range was defined for serum-free thyroxine (FT4) as 7-18 pg/mL, for serum-free triiodothyronine (FT3) as $2.60-4.80 \mathrm{pg} / \mathrm{mL}$, and for TSH as $0.3-4.0 \mathrm{mU} / \mathrm{l}$. The inter-test variation for $\mathrm{FT} 4, \mathrm{FT} 3$, and $\mathrm{TSH}$ was $3.6 \%, 4.1 \%$, and $4.3 \%$, respectively.

\section{Metabolic Parameters}

Several types of tests were used for different parameters: Plasma glucose was measured by enzymatic test; glycosylated hemoglobin A1c (HbA1c) by HPLC method; calcium, phosphate, alanine transaminase, aspartate transaminase, gamma glutamyl transferase alkaline phosphatase, amylase, albumin, total cholesterol, high density lipoprotein (HDL) and triglyceride concentrations by enzymatic colorimetric test; creatinine by Jaffe ' method; c-reactive protein by an immunoassay; blood urea nitrogen by spectrophotometer; potassium, sodium and chlorine levels by ion-selective electrode analysis with an Architect plus (Abbott Park, Illinois, USA) instrument. Serum luteinizing hormone (LH), free testosterone, FT4, TSH and prolactin (PRL) levels were measured by using the radioimmunoassay method (Brahms, Hennigsdorf, Germany). The normal range for $\mathrm{LH}$ was 1-9 IU/L, for free
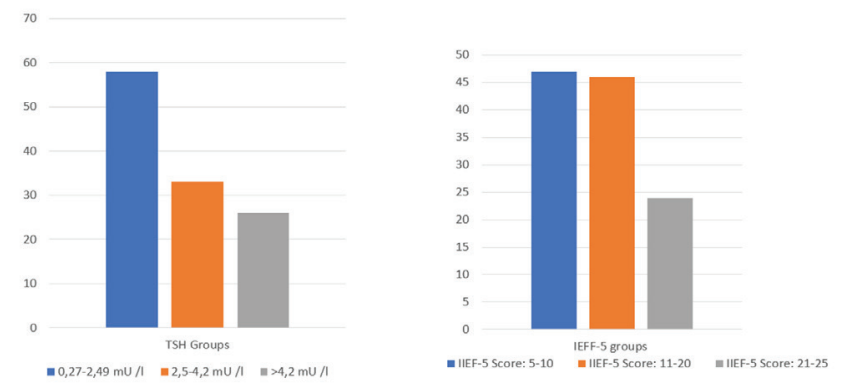

Figure 1. IEFF-5 and TSH groups IIEF-5: International index of erectile function, TSH: Thyroidstimulating hormone 
testosterone was 8.7-54.7 pg/mL, and for PRL was 60-400 $\mu \mathrm{IU} / \mathrm{mL}$. The inter-test variation for $\mathrm{LH}$, free testosterone, and PRL was 3.9\%, $4.7 \%$ and $5.1 \%$, respectively. Patients or controls with abnormal levels of these parameters were excluded from the study. Biochemical blood tests were carried out and levels of hormones were measured. Blood samples were taken from the patients on an empty stomach between 08:00 and 10:00 am. Samples were analyzed simultaneously and in the same laboratory.

\section{Statistical Analyses}

Descriptive statistics (mean, standard deviation, minimum, median, maximum) were used to define continuous variables. The comparison of two independent and normally distributed continuous variables was made with the student's t-test, and the comparison of two independent variables that are not normally distributed was performed with the Mann-Whitney $U$ test. The Pearson correlation coefficient was calculated to determine the relationship between two normally distributed continuous variables, and the Spearman's rho correlation coefficient to determine the relationship between two non-normally distributed continuous variables. Chi-square (or Fisher's Exact test where appropriate) was used to examine the relationship between categorical variables. The statistical significance level was set at 0.05 . The analyses were performed using the MedCalc Statistical Software version 12.7.7 (MedCalc Software Bvba, Ostend, Belgium; http:// www.medcalc.org; 2013) Program.

\section{Results}

While $40 \%$ of the patients participating in the study met the criteria for severe ED and 39\% moderate ED, ED was not present in $21 \%$ of the patients. SCH was detected in 26 of 117 patients included in the study. The demographic data, anthropometric measurements, clinical and biochemical parameters of the patients are summarized in Table 1. The mean age of the patients was $56 \pm 8$ years, the IIEF- 5 score was $13 \pm 6$, the TSH level was $2.70 \pm 1.76 \mathrm{mU} / \mathrm{l}, \mathrm{HbA} 1 \mathrm{c}$ level was $8.95 \% \pm 2.30$, and the duration of diabetes was $8 \pm 7$ years. $49.2 \%$ of the patients participating in the study were smokers. In terms of using antidiabetics, while $32.4 \%$ of the patients were using only oral antidiabetic, $18.7 \%$ were using only insulin. The percentage of patients using both insulin and oral antidiabetic was $48.9 \%$. The patients were first compared according to their IIEF-5 questionnaire scores: 21-25 points, $11-20$ points, and 5-10 points (Table 2). SCH was detected in 17 of 47 patients with severe ED. There was a statistically significant difference between the 3 groups in terms of age, TSH, and duration of ED $(p<0.01$ for all). There was no difference between the IIEF-5 score and parameters such as PRL, testosterone, FSH, HbA1c, glucose, diabetes duration, waist circumference and BMI.

In the correlation analysis between the IIEF- 5 score and other parameters; there was a weak negative correlation between the IIEF-5 score and hemoglobin, and a modest negative correlation between IIEF- 5 age, TSH, and duration of ED (Table 3). In the regression analysis, a 1-unit change in age decreased the IIEF-5 score 0.141-fold, and a 1-unit change in TSH decreased the IIEF-5 score 0.814-fold.

When the patients were divided into 3 groups according to their TSH levels as 0.27-2.49 mU/l, 2.5-4.2 mU/I and $>4.2 \mathrm{mU} / \mathrm{l}$, a significant difference was found between

\begin{tabular}{|c|c|}
\hline $\mathrm{n}=117$ & $\begin{array}{l}\text { Mean } \pm \\
\text { standard } \\
\text { deviation }\end{array}$ \\
\hline Age (years) & $56 \pm 8$ \\
\hline Duration of diabetes (years) & $8 \pm 7$ \\
\hline DED (years) & $5 \pm 4$ \\
\hline IIEF-5 Score & $13 \pm 6$ \\
\hline TSH (0.3-4.0 mU/l) & $2.7 \pm 1.76$ \\
\hline FT3 $(2.60-4.80 \mathrm{pg} / \mathrm{mL})$ & $2.68 \pm 0.43$ \\
\hline FT4 (7-18 pg/mL) & $1.07 \pm 0.22$ \\
\hline Hba1c (\%4.7-\%5.6) & $8.95 \pm 2.3$ \\
\hline Glucose (70-100 mg/dL) & $196 \pm 95$ \\
\hline Prolactin $(60-400 \mu \mathrm{lU} / \mathrm{mL})$ & $8.86 \pm 5.21$ \\
\hline Free testosterone (3.7-54.7 pg/mL) & $4.6 \pm 1.68$ \\
\hline FSH (1.3-19.3 mlU/m) & $5.94 \pm 4.27$ \\
\hline Luteinizing hormone (1-9 IU/L) & $4.63 \pm 2.52$ \\
\hline Sodium (135-145 mEq/L) & $139 \pm 3$ \\
\hline Potassium (3.5-5.5 mmol/L) & $4.55 \pm 0.42$ \\
\hline Creatinine $(<1 \mathrm{mg} / \mathrm{dL})$ & $0.96 \pm 0.29$ \\
\hline Blood urea nitrogen (10-20 mg/dL) & $35.7 \pm 10.86$ \\
\hline AST (15-50 IU/L) & $21 \pm 9$ \\
\hline $\operatorname{ALT}(10-40 \mathrm{U} / \mathrm{L})$ & $30 \pm 29$ \\
\hline C-reactive protein $(<3 \mathrm{mg} / \mathrm{L})$ & $1.41 \pm 3.22$ \\
\hline Hemoglobin (12.4-14.8 g/L) & $14.01 \pm 1.76$ \\
\hline Neutrophil (1.5-8.0 103/uL) & $4.638 \pm 1.506$ \\
\hline Triglyceride (<150 mg/dL) & $184 \pm 137$ \\
\hline $\mathrm{HDL}(40-60 \mathrm{mg} / \mathrm{dL})$ & $38.3 \pm 9.7$ \\
\hline $\mathrm{LDL}(<130 \mathrm{mg} / \mathrm{dL})$ & $147 \pm 115$ \\
\hline Total cholesterol $(<200 \mathrm{mg} / \mathrm{dL})$ & $207 \pm 49$ \\
\hline \multicolumn{2}{|c|}{$\begin{array}{l}\text { DED: Duration of erectile dysfunction, IIEF-5: international index of erectile } \\
\text { function, TSH: Thyroid-stimulating hormone, FT3: serum-free triiodothyronine } \\
\text { FT4: Serum-free thyroxine, HbA1c: Glycolyzed hemoglobin A1c, AST: } \\
\text { Aspartate aminotransferase, FSH: Follicular stimulant hormone, ALT: Alanine } \\
\text { aminotransferase, HDL: High-density lipoprotein, LDL: Low-density lipoprotein }\end{array}$} \\
\hline
\end{tabular}


the groups in terms of age, the IIEF-5 score, duration of ED and hemoglobin levels (Table 4). The IIEF-5 score was statistically lower in the $\mathrm{SCH}$ group.

In the correlation analysis between the TSH level and other parameters (Table 3); a weak statistically significant positive correlation was found between the TSH level and age, hemoglobin, and alanine aminotransferase $(r=$ $0.210, p=0.023 ; r=0.217, p=0.019, r=0.202, p=0.029$, respectively).

\section{Discussion}

In this study, we investigated a possible relationship between ED and $\mathrm{SCH}$ in men with T2DM. We found a clear relationship between ED and $\mathrm{SCH}$ in men with the diagnosis of T2DM. In this patient group, we found that while the TSH level increased, the IIEF-5 score decreased and as the IIEF-5 score decreased the TSH level increased.
ED, which is defined as the persistence and/or failure of sufficient penile erection for successful sexual intercourse, is more common in men with a diagnosis of T2DM $(15,16)$. In epidemiological studies, it has been shown that approximately 30 to $90 \%$ of men with T2DM have ED $(17,18)$. In the Massachusetts Male Aging Study, ED was shown to be 3 times higher in diabetic men compared to non-diabetics (19). The prevalence of severe ED in diabetic patients included in our study was $40 \%$ and moderate ED was 39\%. Our study had a higher prevalence of diabetic ED than previously reported studies. This may be due to the differences in demographic and clinical characteristics of the patients in this study from patients in previous studies. The pathophysiology of ED is multifactorial. Mainly, hypogonadism, diabetic neuropathy and endothelial dysfunction are blamed (20). However, endocrine disorders can also cause ED. Low serum testosterone,

\begin{tabular}{|c|c|c|c|c|}
\hline & $\begin{array}{l}\text { IIEF-5 Score: } 5-10 \\
(n=47) \\
\text { Avr } \pm \text { SD }\end{array}$ & $\begin{array}{l}\text { IIEF-5 Score: } 11-20 \\
(n=46) \\
\text { Avr } \pm \text { SD }\end{array}$ & $\begin{array}{l}\text { IIEF-5 Score: } 21-25 \\
(n=24) \\
\text { Avr } \pm \text { SD }\end{array}$ & $\mathbf{p}$ \\
\hline Age (years) & $59.1 \pm 7.6$ & $56.1 \pm 7.2$ & $51.5 \pm 5.9$ & $<0.001^{*}$ \\
\hline Duration of diabetes (years) & $9.2 \pm 8.4$ & $8.4 \pm 7.1$ & $6.1 \pm 4.7$ & 0.852 \\
\hline DED (years) & $6.9 \pm 4.1$ & $4.9 \pm 3.6$ & 0 & $<0.001^{*}$ \\
\hline TSH (0.3-4.0 mU/L) & $3.3 \pm 1.4$ & $2.5 \pm 1.9$ & $1.7 \pm 1.4$ & $<0.001^{*}$ \\
\hline FT3 $(2.60-4.80 \mathrm{pg} / \mathrm{mL})$ & $2.7 \pm 0.4$ & $2.7 \pm 0.4$ & $2.7 \pm 0.4$ & 0.435 \\
\hline FT4 (7-18 pg/mL) & $1.1 \pm 0.1$ & $1.1 \pm 0.3$ & $1.02 \pm 0.2$ & 0.406 \\
\hline Hba1c (\%4.7-\%5.6) & $8.9 \pm 2.1$ & $8.6 \pm 2.3$ & $9.4 \pm 2.7$ & 0.424 \\
\hline Glucose (70-100 mg/dL) & $198.7 \pm 101.1$ & $192.3 \pm 84.7$ & $197.6 \pm 109$ & 0.915 \\
\hline Prolactin $(60-400 \mu \mathrm{lU} / \mathrm{mL})$ & $9.4 \pm 6.1$ & $8.4 \pm 4.7$ & $8.7 \pm 4.4$ & 0.693 \\
\hline Free testosterone (3.7-54.7 pg/mL) & $4.8 \pm 1.9$ & $4.7 \pm 1.5$ & $4.01 \pm 1.2$ & 0.241 \\
\hline FSH (1.3-19.3 mlU/mL) & $6.5 \pm 4.06$ & $5.4 \pm 4.8$ & $5.9 \pm 3.4$ & 0.706 \\
\hline Luteinizing hormone (1-9 IU/L) & $4.7 \pm 2.2$ & $4.6 \pm 2.9$ & $4.7 \pm 2.2$ & 0.84 \\
\hline Sodium (135-145 mEq/L) & $138.9 \pm 2.6$ & $139.8 \pm 2.9$ & $138.4 \pm 4.2$ & 0.091 \\
\hline Potassium (3.5-5.5 mmol/L) & $4.5 \pm 0.4$ & $4.6 \pm 0.3$ & $4.6 \pm 0.5$ & 0.829 \\
\hline Creatinine $(<1 \mathrm{mg} / \mathrm{dL})$ & $1.007 \pm 0.4$ & $0.9 \pm 0.2$ & $0.9 \pm 0.2$ & 0.366 \\
\hline Blood urea nitrogen $(10-20 \mathrm{mg} / \mathrm{dL})$ & $35.8 \pm 9.7$ & $36.05 \pm 10.6$ & $35.1 \pm 13.7$ & 0.974 \\
\hline AST (15-50 IU/L) & $21.04 \pm 6.5$ & $20.3 \pm 8.7$ & $22.8 \pm 7.6$ & 0.159 \\
\hline ALT (10-40 U/L) & $27.6+16.5$ & $28.8+22.4$ & $35.9+51.5$ & 0.168 \\
\hline C-reactive protein $(<3 \mathrm{mg} / \mathrm{L})$ & $1.36 \pm 1.7$ & $1.1 \pm 1.1$ & $0.8 \pm 0.8$ & 0.222 \\
\hline Hemoglobin $(12.4-14.8 \mathrm{~g} / \mathrm{l})$ & $14.4 \pm 1.2$ & $14.2 \pm 1.6$ & $13.3 \pm 1.7$ & 0.117 \\
\hline Neutrophil (1.5-8.0 103/uL) & $4.8 \pm 1.7$ & $4.5 \pm 1.2$ & $4.7 \pm 1.6$ & 0.897 \\
\hline Triglyceride (<150 mg/dL) & $188.4 \pm 178.3$ & $163.3 \pm 92.1$ & $206.9 \pm 113.1$ & 0.404 \\
\hline HDL cholesterol (40-60 mg/dL) & $40.1 \pm 10.2$ & $37.9 \pm 8.5$ & $36.4 \pm 9.6$ & 0.53 \\
\hline LDL cholesterol (<130 mg/dL) & $156.3 \pm 166.3$ & $129.1 \pm 37.6$ & $166.2 \pm 93.2$ & 0.22 \\
\hline Total cholesterol $(<200 \mathrm{mg} / \mathrm{dL})$ & $208.9 \pm 59.9$ & $200.8 \pm 44.8$ & $215.2 \pm 35.03$ & 0.613 \\
\hline \multicolumn{5}{|c|}{$\begin{array}{l}\text { Avr: Average, SD: Standard deviation, DED: Duration of erectile dysfunction, IIEF-5: International index of erectile function, TSH: Thyroid-stimulating hormone, FT3: Serum } \\
\text { free triiodothyronine FT4: Serum-free thyroxine, HbA1c: Glycolyzed hemoglobin A1C, AST: Aspartate Aminotransferase, FSH: Follicular stimulant hormone, ALT: Alanin } \\
\text { aminotransferase, HDL: High density lipoprotein, LDL: Low density lipoprotein } \\
\text { *Kruskal-Wallis test was used. There was a statistically significant difference between the IEFF-5 groups in terms of age, TSH, and duration of ED }\end{array}$} \\
\hline
\end{tabular}




\begin{tabular}{|c|c|c|c|}
\hline & & IIEF-5 score & TSH level \\
\hline \multirow{2}{*}{ Age (years) } & $r$ & $-0.431^{*}$ & $0.21^{*}$ \\
\hline & $p$ & $<0.001$ & 0.023 \\
\hline \multirow{2}{*}{ Duration of Diabetes (years) } & $r$ & -0.079 & 0.111 \\
\hline & $p$ & 0.398 & 0.232 \\
\hline \multirow{2}{*}{ DED (years) } & $r$ & $-0.642^{*}$ & $0.404^{*}$ \\
\hline & $p$ & $<0.001$ & $<0.001$ \\
\hline \multirow{2}{*}{ IIEF-5 Score } & $r$ & 1 & $-0.453^{*}$ \\
\hline & $p$ & & $<0.001$ \\
\hline \multirow{2}{*}{ TSH (0.3-4.0 mU/I) } & $r$ & $-0.453^{*}$ & 1 \\
\hline & $p$ & $<0.001$ & \\
\hline \multirow{2}{*}{ FT3 (2.60-4.80 pg/mL) } & $r$ & -0.028 & -0.002 \\
\hline & $p$ & 0.768 & 0.986 \\
\hline \multirow{2}{*}{ FT4 (7-18 pg/mL) } & $\mathrm{R}$ & -0.067 & -0.014 \\
\hline & $p$ & 0.476 & 0.88 \\
\hline \multirow{2}{*}{$\mathrm{Hba1c}(\% 4.7-\% 5.6)$} & $r$ & -0.027 & 0.017 \\
\hline & $p$ & 0.775 & 0.856 \\
\hline \multirow{2}{*}{ Glucose (70-100 mg/dL) } & $r$ & -0.064 & 0.139 \\
\hline & $p$ & 0.493 & 0.136 \\
\hline \multirow{2}{*}{ Prolactin $(60-400 \mu \mathrm{IU} / \mathrm{mL})$} & $r$ & -0.054 & 0.019 \\
\hline & $p$ & 0.564 & 0.839 \\
\hline \multirow{2}{*}{$\begin{array}{l}\text { Free testosterone }(3.7-54.7 \mathrm{pg} / \\
\mathrm{mL})\end{array}$} & $r$ & -0.164 & 0.092 \\
\hline & $p$ & 0.077 & 0.324 \\
\hline \multirow{2}{*}{ FSH (1.3-19.3 mlU/mL) } & $r$ & -0.015 & -0.05 \\
\hline & $p$ & 0.874 & 0.595 \\
\hline \multirow{2}{*}{ Luteinizing Hormone (1-9 IU/L) } & $r$ & 0.033 & -0.146 \\
\hline & $p$ & 0.721 & 0.117 \\
\hline \multirow{2}{*}{ Sodium (135-145 mEq/L) } & $r$ & 0.022 & -0.088 \\
\hline & $p$ & 0.811 & 0.347 \\
\hline \multirow{2}{*}{ Potassium (3.5-5.5 mmol/L) } & $r$ & 0.039 & -0.119 \\
\hline & $p$ & 0.678 & 0.202 \\
\hline \multirow{2}{*}{ Creatinin (<1 mg/dL) } & $r$ & -0.144 & 0.056 \\
\hline & $p$ & 0.121 & 0.545 \\
\hline \multirow{2}{*}{$\begin{array}{l}\text { Blood Urea Nitrogen (10-20 mg/ } \\
d L)\end{array}$} & $r$ & -0.035 & -0.092 \\
\hline & $p$ & 0.708 & 0.326 \\
\hline \multirow{2}{*}{ AST (15-50 IU/L) } & $r$ & 0.019 & -0.017 \\
\hline & $p$ & 0.836 & 0.853 \\
\hline \multirow{2}{*}{$\operatorname{ALT}(10-40 \mathrm{U} / \mathrm{L})$} & $r$ & -0.061 & 0.202 \\
\hline & $p$ & 0.516 & 0.029 \\
\hline \multirow{2}{*}{ C-reactive protein ( $<3 \mathrm{mg} / \mathrm{L}$ ) } & $r$ & -0.11 & 0.148 \\
\hline & $p$ & 0.237 & 0.11 \\
\hline \multirow{2}{*}{ Hemoglobin (12.4-14.8 g/l) } & $r$ & $-0.231^{*}$ & $0.217^{*}$ \\
\hline & $p$ & 0.012 & 0.019 \\
\hline \multirow[t]{2}{*}{ Neutrophil (1.5-8.0 103/uL) } & $r$ & 0.052 & -0.088 \\
\hline & $p$ & 0.576 & 0.348 \\
\hline
\end{tabular}

\begin{tabular}{|l|l|l|l|}
\hline \multirow{2}{*}{ Triglyceride (<150 mg/dL) } & $r$ & 0.078 & 0.115 \\
\cline { 2 - 4 } & $p$ & 0.405 & 0.216 \\
\hline \multirow{2}{*}{ HDL cholesterol (40-60 mg/dL) } & $r$ & -0.102 & -0.121 \\
\cline { 2 - 4 } & $p$ & 0.274 & 0.193 \\
\hline \multirow{2}{*}{ LDL Cholesterol (<130 mg/dL) } & $r$ & 0.085 & -0.055 \\
\cline { 2 - 4 } & $p$ & 0.363 & 0.555 \\
\hline \multirow{2}{*}{ Total Cholesterol (<200 mg/dL) } & $r$ & 0.095 & 0.019 \\
\cline { 2 - 4 } & $p$ & 0.306 & 0.841 \\
\hline $\begin{array}{l}\text { DED: Duration of erectile dysfunction, IIEF-5: International index of } \\
\text { erectile function, TSH: Thyroid-stimulating hormone, FT3: Serum- } \\
\text { free triiodothyronine FT4: Serum-free thyroxine, HbA1c: Glycolyzed } \\
\text { hemoglobin A1c, AST: Aspartate aminotransferase, FSH: Follicular } \\
\text { stimulant hormone, ALT: Alanine aminotransferase, HDL: High-density } \\
\text { lipoprotein, LDL: Low-density lipoprotein } \\
\text { *Spearman's rho p<0.05 (For the correlation between two } \\
\text { continuous variables that are not normally distributed) }\end{array}$ \\
\hline
\end{tabular}

hyperprolactinemia, and hypothyroidism were the most common endocrine abnormalities in patients with sexual dysfunction (21).

In general population screenings, it has been shown that the prevalence of $\mathrm{SCH}$ varies between $4 \%$ and $10 \%$ $(9,10,22)$. The prevalence of SCH in the patients included in our study was $22.2 \%$, and it was slightly higher than the general population. We think that this is since the patients included in our study were diabetic and $\mathrm{SCH}$ was a common endocrine disorder in diabetic patients. Although $\mathrm{SCH}$ is generally an asymptomatic condition, it is known to affect many organs in the body (23). SCH has been shown to be involved in the pathophysiology of atherosclerosis and cardiovascular diseases by causing endothelial dysfunction (23).

$\mathrm{SCH}$ and ED, both of which have multiple mechanisms in their pathogenesis, are increasingly prevalent especially in middle-aged and elderly diabetic male populations and are conditions that decrease physical function, sexual life quality, and quality of life. SCH and ED constitute an important social problem both in our country and in the world, due to their treatment process, costs, complications they cause, and their increasing prevalence in recent years. The association between $\mathrm{SCH}$ and T2DM is well known (24). However, the relationship of SCH to the microvascular complications of diabetes is not clear. Various mechanisms may play a role in the relationship between thyroid dysfunction and microvascular complications in diabetes. First, it has been shown that insulin resistance is associated with clinical and SCH (24). One possible mechanism may be defective fibrinolysis or impaired vasodilation associated with insulin resistance (24). There are several studies evaluating the relationship between thyroid function and microvascular complications such as diabetic retinopathy, neuropathy, and nephropathy in patients with T2DMM, but the results are controversial (25-27). To the best of our knowledge, there are no studies 
investigating the relationship between $\mathrm{SCH}$ and diabetic ED to date. Our results showed that SCH was associated with diabetic ED in 117 type 2 diabetic patients.

Free testosterone levels drop by approximately $40 \%$ in men between the ages of 25 and 75 (3). This condition can cause ED in this age group. However, in our study, we could not find a relationship between $\mathrm{SCH}$ and androgenic hormones such as testosterone. This situation makes us think that $\mathrm{SCH}$ causes hormone-independent ED in this patient group. At this point, as shown in our study, the IIEF-5 score in the SCH group was lower than the normal group. Therefore, we believe that there are different common pathways in the pathophysiology of SCH and ED in diabetic men.
Thyroid dysfunction can affect body growth metabolism and the synthesis and secretion of sex steroids (28). Numerous clinical studies have shown that both hyperthyroidism and hypothyroidism cause sexual and reproductive problems $(28,29)$. Additionally, it is known that thyroid hormone level affects Leydig cells, Sertoli cells and spermatogenesis. It has been shown that the risk of developing ED is higher in men with hypothyroidism (29). Our study revealed that this condition occurs when $\mathrm{SCH}$ is present.

It has been shown that $\mathrm{SCH}$ suppresses antioxidative capacity by reducing paraoxonase and arylesterase activities (30). Increased oxidative stress may play an important role in the pathogenesis of diabetes-related

\begin{tabular}{|c|c|c|c|c|}
\hline & \multirow{2}{*}{$\begin{array}{l}\begin{array}{l}\text { TSH level: } 0.27-2.49 \\
\mathrm{mU} / \mathrm{l}(\mathrm{n}=58)\end{array} \\
\text { Avr } \pm \text { SD } \\
\end{array}$} & \multirow{2}{*}{$\begin{array}{l}\text { TSH level: } 2.5-4.2 \\
\mathrm{mU} / \mathrm{L}(\mathrm{n}=33) \\
\mathrm{Avr} \pm \mathrm{SD}\end{array}$} & \multirow{2}{*}{\begin{tabular}{|l|}
$\begin{array}{l}\text { TSH level }>4.2 \mathrm{mU} / \mathrm{L} \\
(\mathrm{n}=26)\end{array}$ \\
Avr $\pm \mathrm{SD}$
\end{tabular}} & \multirow{2}{*}{ p } \\
\hline & & & & \\
\hline Age (years) & $54.4 \pm 6.9$ & $59.4 \pm 8.1$ & $57.3 \pm 7.7$ & $0.015^{*}$ \\
\hline Duration of diabetes (years) & $7.2 \pm 5.8$ & $9.8 \pm 8.4$ & $8.6 \pm 8.6$ & 0.384 \\
\hline DED (years) & $2.8 \pm 3.5$ & $7.7 \pm 4.2$ & $5.2 \pm 3.8$ & $<0.001^{*}$ \\
\hline IIIEF5 score & $16.2 \pm 5.7$ & $10.1 \pm 5.8$ & $9.6 \pm 5.8$ & $<0.001^{*}$ \\
\hline FT3 $(2.60-4.80 \mathrm{pg} / \mathrm{mL})$ & $2.7 \pm 0.4$ & $2.7 \pm 0.4$ & $2.6 \pm 0.5$ & 0.932 \\
\hline FT4 (7-18 pg mL) & $1.1 \pm 0.2$ & $1.02 \pm 0.1$ & $1.1 \pm 0.2$ & 0.222 \\
\hline Hba1c (\%4.7-\%5.6) & $8.9 \pm 2.4$ & $9 \pm 2.2$ & $9.1 \pm 2.3$ & 0.821 \\
\hline Glucose $(70-100 \mathrm{mg} / \mathrm{dL})$ & $186.3 \pm 92.7$ & $212.1 \pm 112.1$ & $198.6 \pm 81.1$ & 0.422 \\
\hline Prolactin $(60-400 \mu \mathrm{lU} / \mathrm{mL})$ & $8.7 \pm 4.8$ & $9.1 \pm 3.8$ & $8.9 \pm 7.5$ & 0.301 \\
\hline Free testosterone $(3.7-54.7 \mathrm{pg} / \mathrm{mL})$ & $4.4 \pm 1.7$ & $5.1 \pm 1.9$ & $4.5 \pm 1.2$ & 0.311 \\
\hline FSH (1.3-19.3 mlU/mL) & $5.3 \pm 2.8$ & $5.9 \pm 2.8$ & $6.3 \pm 5.1$ & 0.434 \\
\hline Luteinizing hormone (1-9 IU/L) & $4.6 \pm 1.9$ & $4.7 \pm 2.5$ & $3.9 \pm 1.9$ & 0.305 \\
\hline Sodium (135-145 mEq/L) & $139.2 \pm 3.5$ & $139.1 \pm 2.8$ & $139.04 \pm 2.9$ & 0.544 \\
\hline Potassium (3.5-5.5 mmol/L) & $4.6 \pm 0.4$ & $4.6 \pm 0.4$ & $4.4 \pm 0.3$ & 0.254 \\
\hline Creatinin (<1 mg/dL) & $0.9 \pm 0.2$ & $1.08 \pm 0.4$ & $0.9 \pm 0.1$ & 0.461 \\
\hline Blood urea nitrogen $(10-20 \mathrm{mg} / \mathrm{dL})$ & $35.8 \pm 11.2$ & $36.4 \pm 12.1$ & $34 \pm 8.7$ & 0.769 \\
\hline AST (15-50 IU/L) & $21.2 \pm 8.7$ & $21.4 \pm 6.9$ & $22.1 \pm 10.8$ & 0.924 \\
\hline ALT (10-40 U/L) & $29.3 \pm 37.6$ & $31.1 \pm 17.9$ & $31.4 \pm 20.5$ & 0.212 \\
\hline C-reactive protein $(<3 \mathrm{mg} / \mathrm{L})$ & $1.1 \pm 1.2$ & $1.01 \pm 1.4$ & $2.6 \pm 6.3$ & 0.299 \\
\hline Hemoglobin (12.4-14.8 g/L) & $13.7 \pm 1.7$ & $14.4 \pm 1.4$ & $14.2 \pm 2.2$ & $0.036^{*}$ \\
\hline Neutrophil (1.5-8.0 103/ul) & $4.6 \pm 1.3$ & $5.1 \pm 1.9$ & $4.1 \pm 1.05$ & 0.078 \\
\hline Triglyceride $(<150 \mathrm{mg} / \mathrm{dL})$ & $170.3 \pm 97.1$ & $210.5 \pm 214.6$ & $177.3 \pm 75.9$ & 0.522 \\
\hline HDL cholesterol (40-60 mg/dL) & $39 \pm 9$ & $39.7 \pm 11.3$ & $35.1 \pm 8.6$ & 0.171 \\
\hline LDL cholesterol (<130 mg/dL) & $141.9 \pm 58.6$ & $177.8 \pm 198.5$ & $122.04 \pm 37.8$ & 0.113 \\
\hline Total cholesterol $(<200 \mathrm{mg} / \mathrm{dL})$ & $205.9 \pm 39.3$ & $219.2 \pm 66.8$ & $196.4 \pm 41.5$ & 0.23 \\
\hline $\begin{array}{l}\text { Avr: Average, SD: Standard deviation, DEI } \\
\text { free triiodothyronine FT4: Serum-free thy } \\
\text { aminotransferase, HDL: High density lipo } \\
\text { *Kruskal-Wallis test was used. There was } \\
\text { levels }\end{array}$ & $\begin{array}{l}\text {, IIEF-5: International inde } \\
\text { globin A1c, AST: Aspartat } \\
\text { ein } \\
\text { ee TSH groups in terms of a }\end{array}$ & $\begin{array}{l}x \text { of erectile function, } \\
\text { e aminotransferase, } F \\
\text { ge, the IIEF-5 score, du }\end{array}$ & $\begin{array}{l}\text { Thyroid-stimulating hormo } \\
\text { Follicular stimulant hormon } \\
\text { on of erectile dysfunction an }\end{array}$ & e, FT3: Seru \\
\hline
\end{tabular}


complications. SCH can also cause endothelial dysfunction by causing thickening of the basement membrane (30). In our study, we believe that SCH causes ED by affecting cardiac function, peripheral vascular resistance, endothelial function, and renal hemodynamics.

In addition, it has been proven that high TSH concentration causes endothelial dysfunction by reducing the formation and availability of nitric oxide (NO) (16). It is well known that NO plays an important role in the relaxation of the corporal smooth muscle and vascular system to initiate and maintain erection (3). This pathway may be one of the possible mechanisms between $\mathrm{SCH}$ and ED in our study.

\section{Study Limitations}

Our study had some limitations. First, our study was single center cross-sectional analysis. We could not establish a causal relationship between $\mathrm{SCH}$ and diabetic ED. Second, thyroid function was evaluated at a single time point. Third, the definition of ED was based on a onetime measurement. Despite all these limitations, to the best of our knowledge, there is no study in the literature evaluating the relationship between ED and $\mathrm{SCH}$ in men with T2DM so that the present study is valuable for being the first study in the literature on this subject.

\section{Conclusion}

This study revealed that $\mathrm{SCH}$ is closely associated to ED in diabetic men. We recommend conducting thyroid function tests in diabetic men with ED and screening for ED in men with $\mathrm{SCH}$. However, large randomized controlled clinical studies are needed to determine whether there is a true relationship between $\mathrm{SCH}$ and ED in diabetic patients.

\section{Authorship Contributions}

Concept: S.U.B., Design: R.S., S.U.B., Data Collection or Processing: R.S., S.U.B., Analysis or Interpretation: A.B., Literature Search: R.S., S.U.B., Writing: R.S., S.U.B., O.B.

Conflict of Interest: No conflict of interest was declared by the authors.

Financial Disclosure: The authors declared that this study received no financial support.

\section{References}

1. DeFronzo RA, Ferrannini E, Groop L, et al. Type 2 diabetes mellitus. Nat Rev Dis Primers 2015;1:15019.

2. Veelen A, Erazo-Tapia E, Oscarsson J, Schrauwen P. Type 2 diabetes subgroups and potential medication strategies in relation to effects on insulin resistance and beta-cell function: A step toward personalised diabetes treatment? Mol Metab 2020;101158.

3. Salonia A, Bettocchi C, Boeri L, et al. European Association of Urology Guidelines on Sexual and Reproductive Health-2021 Update: Male Sexual Dysfunction. Eur Urol 2021;80:333-57.
4. Kouidrat Y, Pizzol D, Cosco T, et al. High prevalence of erectile dysfunction in diabetes: a systematic review and metaanalysis of 145 studies. Diabet Med 2017;34:1185-92.

5. Wang $X Y$, Huang $W$, Zhang $Y$. Relation between hypertension and erectile dysfunction: a meta-analysisof cross-section studies. Int J Impot Res 2018;30:141-6.

6. Leisegang K, Sengupta P, Agarwal A, Henkel R. Obesity and male infertility: Mechanisms and management. Andrologia 2021;53:e13617.

7. Lotti F, Maseroli E, Fralassi N, et al. Is thyroid hormones evaluation of clinical value in the work-up of males of infertile couples? Hum Reprod 2016;31:518-29.

8. Patel N, Kashanian JA. Thyroid Dysfunction and Male Reproductive Physiology. Semin Reprod Med 2016;34:35660.

9. Yoo WS, Chung HK. Subclinical Hypothyroidism: Prevalence, Health Impact, and Treatment Landscape. Endocrinol Metab (Seoul) 2021;36:500-13.

10. Štěpánek L, Horáková $D$, Štěpánek $L$, et al. Free triiodothyronine/free thyroxine (FT3/FT4) ratio is strongly associated with insulin resistance in euthyroid and hypothyroid adults: a cross-sectional study. Endokrynol Pol 2021;72:8-13.

11. American Diabetes Association. 2. Classification and Diagnosis of Diabetes: Standards of Medical Care in Diabetes-2021. Diabetes Care 2021;44(Suppl 1):15-33.

12. Rosen RC, Cappelleri JC, Smith MD, Lipsky J, Peña BM. Development and evaluation of an abridged, 5-item version of the International Index of Erectile Function (IIIEF-5) as a diagnostic tool for erectile dysfunction. Int J Impot Res 1999;11:319-26.

13. Turunc T, Deveci S, Güvel S, Peşkircioğlu L. The assessment of Turkish validation with 5 question version of International Index of Erectile Function (IIEF-5). Turk J Urol 2007;33:45-9.

14. Peeters RP. Subclinical Hypothyroidism. N Engl J Med 2017;376:2556-65.

15. Cripps SM, Mattiske DM, Pask AJ. Erectile Dysfunction in Men on the Rise: Is There a Link with Endocrine Disrupting Chemicals? Sex Dev 2021;16:1-26.

16. Fan J, Peng T, Hui J, et al. Erectile Dysfunction in Type-2 Diabetes Mellitus Patients: Predictors of Early Detection and Treatment. Urol Int 2021:1-7.

17. Kouidrat Y, Pizzol D, Cosco T, et al. High prevalence of erectile dysfunction in diabetes: a systematic review and metaanalysis of 145 studies. Diabet Med 2017;34:1185-92.

18. Walle $B$, Lebeta KR, Fita YD, Abdissa HG. Prevalence of erectile dysfunction and associated factors among diabetic men attending the diabetic clinic at Felege Hiwot Referral Hospital, Bahir Dar, North West Ethiopia, 2016. BMC Res Notes 2018;11:130.

19. Feldman HA, Goldstein I, Hatzichristou DG, Krane RJ, McKinlay JB. Impotence and its medical and psychosocial 
correlates: results of the Massachusetts Male Aging Study. J Urol 1994;151:54-61.

20. Echeverri Tirado LC, Ferrer JE, Herrera AM. Aging and Erectile Dysfunction. Sex Med Rev 2016;4:63-73.

21. Sansone A, Romanelli F, Gianfrilli D, Lenzi A. Endocrine evaluation of erectile dysfunction. Endocrine 2014;46:42330.

22. Biondi B, Cappola AR, Cooper DS. Subclinical Hypothyroidism: A Review. JAMA 2019;322:153-60.

23. Delitala AP, Fanciulli G, Maioli M, Delitala G. Subclinical hypothyroidism, lipid metabolism and cardiovascular disease. Eur J Intern Med 2017;38:17-24.

24. Biondi B, Kahaly GJ, Robertson RP. Thyroid Dysfunction and Diabetes Mellitus: Two Closely Associated Disorders. Endocr Rev 2019;40:789-824.

25. Qi Q, Zhang QM, Li CJ, et al. Association of Thyroid-Stimulating Hormone Levels with Microvascular Complications in Type 2 Diabetes Patients. Med Sci Monit 2017;23:2715-20.
26. Yang GR, Yang JK, Zhang L, An YH, Lu JK. Association between subclinical hypothyroidism and proliferative diabetic retinopathy in type 2 diabetic patients: a case-control study. Tohoku J Exp Med 2010;222:303-10.

27. Chen HS, Wu TE, Jap TS, Lu RA, Wang ML, Chen RL, et al. Subclinical hypothyroidism is a risk factor for nephropathy and cardiovascular diseases in Type 2 diabetic patients. Diabet Med 2007;12:1336-44.

28. Li YM, Yao B. (Influence of thyroid dysfunction on male sexual and reproductive functions and its mechanisms). Zhonghua Nan Ke Xue 2016;22:741-5.

29. Krassas GE, Tziomalos K, Papadopoulou F, Pontikides N, Perros P. Erectile dysfunction in patients with hyper- and hypothyroidism: how common and should we treat? J Clin Endocrinol Metab 2008;93:1815-9.

30. Cebeci E, Alibaz-Oner F, Usta M, Erguney M. Evaluation of oxidative stress, the activities of paraoxonase and arylesterase in patients with subclinical hypothyroidism. J Investig Med 2012;60:23-8. 